\title{
Commentary
}

\section{Pay Walled Retraction Notices}

\author{
Jaime A. Teixeira da Silva \\ P. O. Box 7, Miki-cho post office, Ikenobe 3011-2, Kagawa-ken, \\ 761-0799, Japan \\ Email: jaimetex@yahoo.com
}

\begin{abstract}
A retraction of a scientific paper is made, most often due to errors or lack of publishing ethics on the part of authors, or, on occasion, duplicate publication by a publisher in error. The retraction notice that accompanies the retraction is an extremely important document, because it is the only information that provides a background to the public regarding the reason why the manuscript was retracted. In most cases, if the retraction notice is truly transparent, it will contain a few sentences that indicate the reason, and possibly also the authors' responsible, among other facts. According to the Committee on Publication Ethics (COPE), retraction notices should be free to view, i.e. open access. This opinion piece exposes how several publishers are selling access to retraction notices, including COPE members, despite, in some cases, being paying COPE members. The business and academic ethics of such an action is thus called into question.
\end{abstract}

Key words: accountability, COPE, errors, ethics, free, literature correction, open access

\section{Retraction Notices: The Window on Retractions}

When scientists commit misconduct, fabricate or duplicate data, plagiarize the work of others, or their own (selfplagiarism), due to malice or to honest error, or on occasion when a publisher accidentally publishes a paper in duplicate, the most likely outcome, if such an error is detected, is a retraction ${ }^{1}$. Greater awareness and tools to detect such cases have most likely been the reason for a spike in the number of journals issuing retractions ${ }^{2}$. Retraction notices thus serve not only to correct the literature, they also serve as important historical documents that inform, and alert, peers and the wider scientific public, that errors exist in that scientific paper, most likely as a result of the permeability and imperfection of the traditional peer review system ${ }^{3,4}$.

Retractions (and also errata, corrigenda and expressions of concern) need to be issued quickly, openly and transparently, and should be informative. In most cases, the correct way to represent a retraction is with a prominent red, water-marked "RETRACTION" stamped across each page of the original retracted PDF file or HTML content online. In most cases, publishers tend to publish a PDF file as the retraction notice and this may or may not have an equivalent HTML text. The retraction notice is thus an important document that bridges the divide between what other scientists or peers can see, and what the propents of the retraction (i.e., the authors, the editors, and the publisher) know. The document is important, and is in fact an essential complement to the public academic record. The importance of the public nature of the notice becomes greater when we are dealing with scentists who have either received public funding, or whose paid salaries are based on tax-payers' (i.e., public) funds. The same principle applies to corrections or corrigenda, or to errata, which point out other errors in the manuscript, but which do not necessarily result in a retraction.

\section{Retraction Notices should be Open to the Public}


One of the salient points regarding retraction notices specified in the COPE (Committee on Publication Ethics) retraction guidelines (COPE 2015) ${ }^{5}$ is that " Notices of retraction should ... be freely available to all readers (i.e. not behind access barriers or available only to subscribers)." COPE consists of, on the 13th July 2015, 10,124 members (http://publicationethics.org/members). One would thus expect that paying COPE member journals and publishers would follow the rules and guidelines set out for them by COPE. Thus, should any COPE member be charging money for access to retraction notices, would this not be a direct violation of COPE's code of conduct? Should non-COPE members adhere to the same principle? Despite this, several journals and publishers, some of which are COPE members, are selling the retraction (or expression of concern, errata, or corrigenda) notices (10 cases shown in Appendix 1).

\section{Questioning Pay Walled Retraction Notices}

The morality of the business model in which information should be freely available to other scientists and the public, but is not, but is instead sold for a profit, is thus highly questionable. In most cases, the retraction notice is a PDF file, sometimes only a single page long, with information that is vital to public understanding, yet is sold for a few dozen US\$. The ethics of the business model employed by COPE members then becomes questioned when we are dealing explicitly with COPE members that are issuing retraction notices behind a pay wall, even though COPE has explicitly indicated that the best practice is not to do so. One of the academic and corporate responsibilities of publishers is to be consistent with the ethics and the rules of engagement that they impose upon the authorship ${ }^{6}$. If, however, a publisher is unable to respect the principles by which it claims to abide by, then what does this say about the business model, or the ethics, of that publisher?

\section{Conclusions}

Retractions are becoming increasingly part and parcel of the publishing platform. Retraction notices serve as the only information available to the public informing them of the background. Thus, they should be both open, and free to view. This issue needs wider and more serious debate and greater enforcement by COPE of COPE members. Those publishers that are not COPE members need to reflect on the ethics of selling information that is vital to other scientists and the public. Post-publication peer review is one tool that allows scientists to identify such discrepancies between publisher's stated norms, guidelines and ethics, and their actual practice, and bring them to the attention of the wider scientific community ${ }^{7}$. The porous nature of COPE's clause 3.1 of its code of conduct for editors is another issue of concern related to COPE and COPE member journals and publishers ${ }^{8}$.

Conflicts of interest: The author declares no conflicts of interest. Copyrighted images in screen-shots used under the fair use agreement: http://en.wikipedia.org/wiki/Fair use. The author declares that information related to COPE members and the status of free vs paid in the screen-shots of the retraction notices remains valid, at least until the date of acceptance of this paper.

\section{References:}

1. Fang FC, Steen RG, Casadevall A. Misconduct accounts for the majority of retracted scientific publications. Proc Natl Acad Sci USA 2012; 109: 17028-17033. DOI: 10.1073/pnas.1212247109

2. Fanelli D. Why growing retractions are (mostly) a good sign. PLoS Med 2013; 10(12): e1001563. doi:10.1371/journal.pmed.1001563

3. Teixeira da Silva JA. The importance of retractions and the need to correct the downstream literature. J Scientific Exploration 2015; 29(2): 353-356.

4. Teixeira da Silva JA, Dobránszki J. Problems with traditional science publishing and finding a wider niche for post-publication peer review. Accountability Res: Policies Quality Assurance 2015; 22(1): 22-40. DOI: 10.1080/08989621.2014.899909 
5. COPE (Committee on Publication Ethics) (2015) http://publicationethics.org/files/retraction\%20guidelines.pdf (last accessed 18 May, 2015)

6. Teixeira da Silva JA. Responsibilities and rights of authors, peer reviewers, editors and publishers: a status quo inquiry and assessment. Asian Australasian J Plant Sci Biotech 2013; 7(Special Issue 1): 6-15.

7. Teixeira da Silva JA. Debunking post-publication peer review: what it is and what it's not. Int J Edu Infor Technol (Public Sci Framework) 2015; 1(2): 34-37.

8. Teixeira da Silva JA. COPE code of conduct clause 3.1. under the microscope: a prelude to unfair rejections. Curr Sci 2015; 109(1): 16-17. 


\section{Appendix 1}

Examples of publishers selling retraction notices (i.e., behind a pay wall), rather than making the files open access. The original reference, the link to the retraction notice URL, the charge as well as whether the publisher is a COPE member, are indicated. Prices and facts valid until July 13, 2015.

Case 1 (Informa Health)

Publisher is COPE member? No

Journal is COPE member? Yes

Lee DB, Suh HS, Choi YS. A comparative study of low-fluence 1,064nm Q-Switched Nd:YAG laser with or without chemical peeling using Jessner's solution in melasma patients. J Cosmetic Laser Ther 2014; 16(6): 264-270. DOI: 10.3109/14764172.2013.864201

Retraction: http://informahealthcare.com/doi/full/10.3109/14764172.2014.998978

The charge to access the retraction notice: US $\$ 52.00$

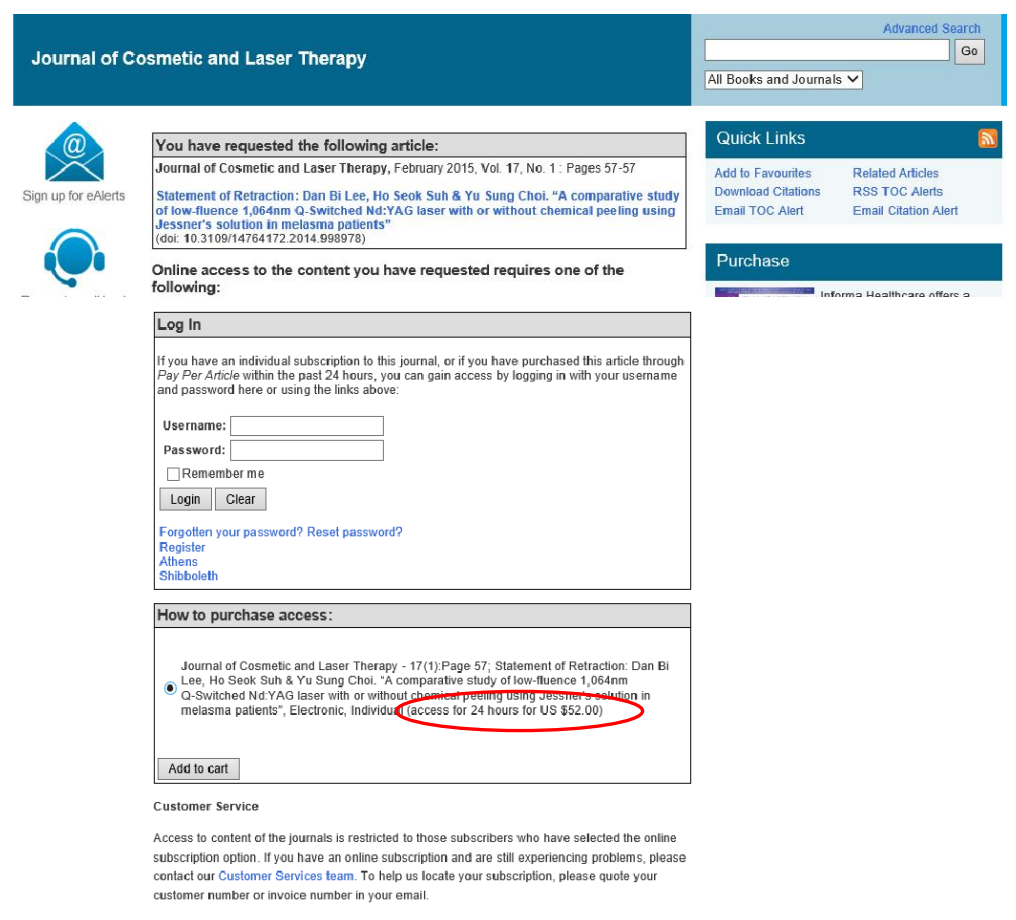


Case 2 (American Physical Society)

Publisher is COPE member? No

Journal is COPE member? No

Puentes G, Gerhardt I, Katzschmann F, Silberhorn C, Wrachtrup J, Lewenstein M. Observation of topological structures in photonic quantum walks. Phys Rev Lett 2014; 112, 120502. DOI: 10.1103/PhysRevLett.112.120502 http://journals.aps.org/prl/abstract/10.1103/PhysRevLett.112.120502

Retraction: http://journals.aps.org/prl/abstract/10.1103/PhysRevLett.113.019901

The charge to access the retraction notice: US $\$ 25.00$

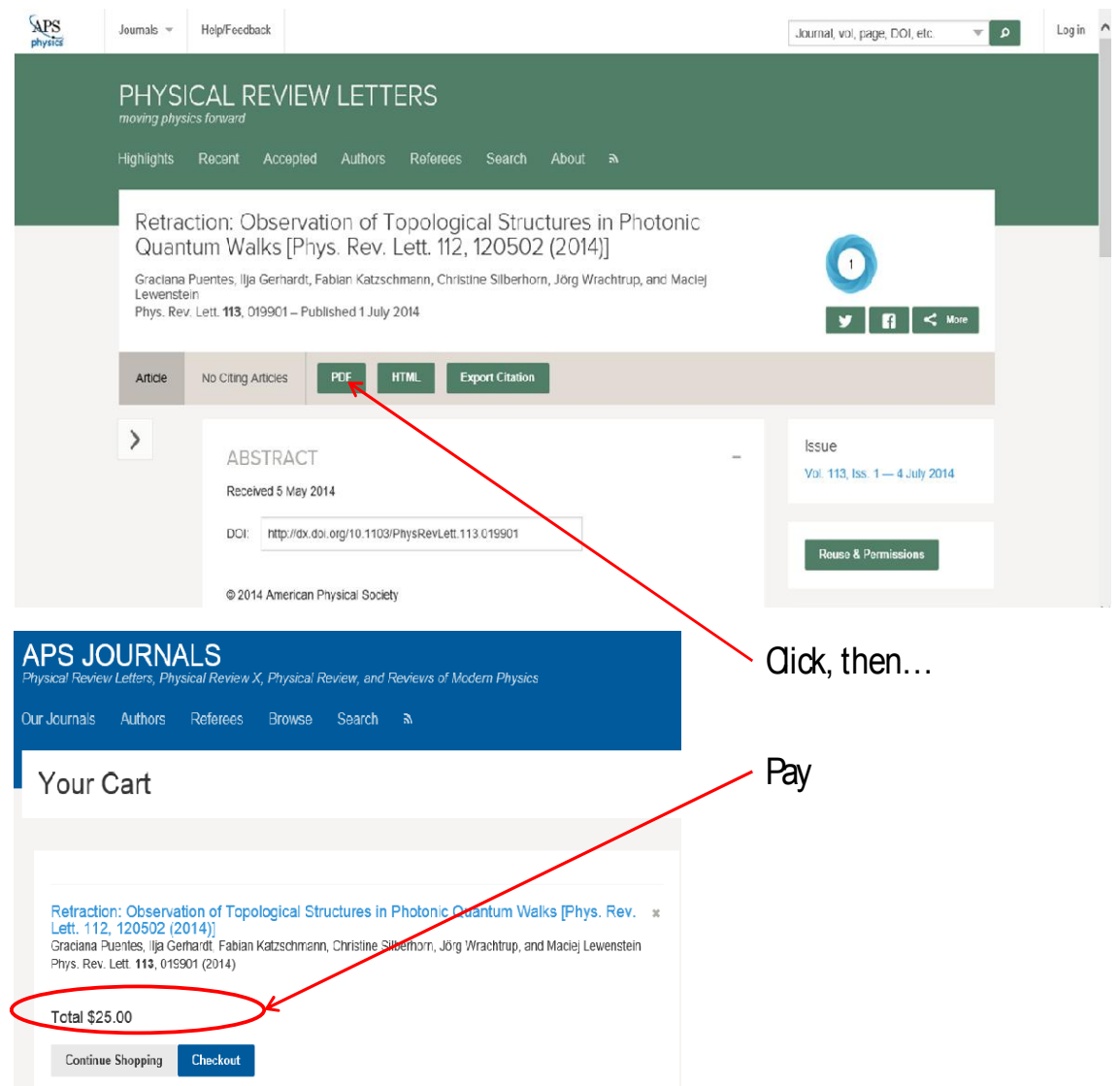


Case 3 (Elsevier) (expression of concern)

Publisher is COPE member? Yes

Journal is COPE member? Yes

Firoz BF, Henning JS, Zarzabal LA, Pollock BH. Toxic epidermal necrolysis: Five years of treatment experience from a burn unit. J Ame Acad Dermatol 2012; 67(4): 630-635. DOI: 10.1016/j.jaad.2011.12.014

http://www.sciencedirect.com/science/article/pii/S0190962211022808

Expression of concern: DOI: 10.1016/j.jaad.2014.06.027

http://www.sciencedirect.com/science/article/pii/S0190962214015886

The charge to access the notice: US $\$ 39.95$

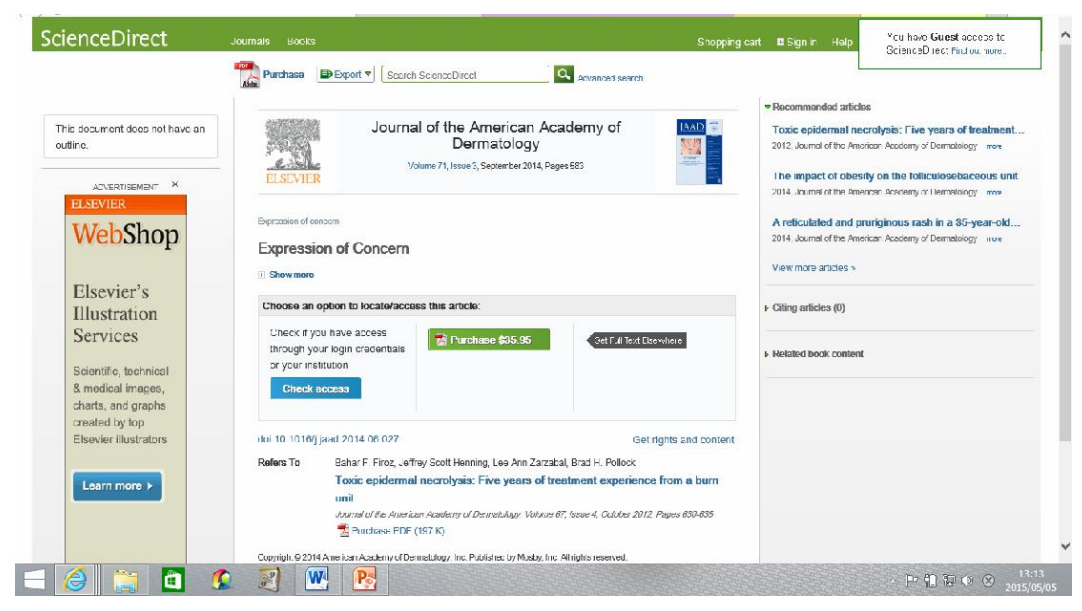


Case 4 (Wiley)

Publisher is COPE member? Yes

Journal is COPE member? No

Fan X, Yang Z, Parker DJ. Flow structure and particle motions in a gas-polyethylene fluidized bed. AIChE J 2007; 67(4): 630-635. DOI: 10.1002/aic.11232

Retraction: http://onlinelibrary.wiley.com/doi/10.1002/aic.11232/full

The charge to access the notice: US $\$ 38$

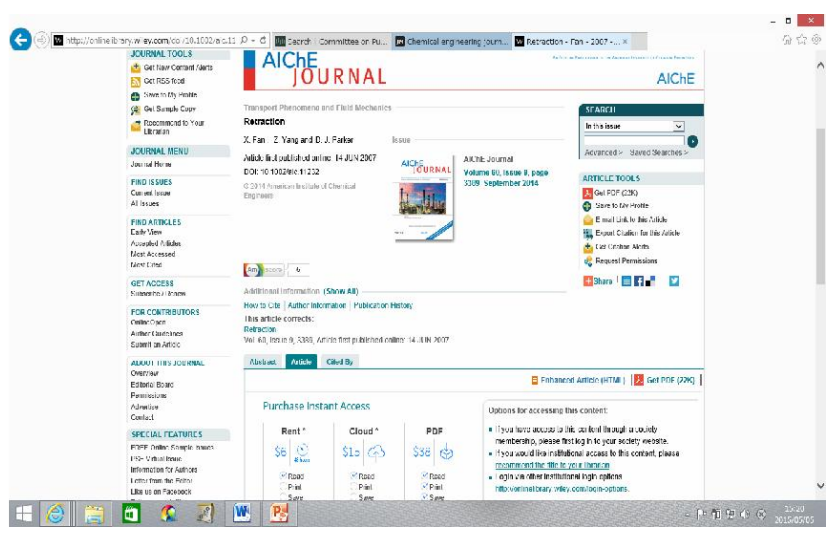


Case 5 (The Royal College of Psychiatrists)

Publisher is COPE member? Unclear

Journal is COPE member? Yes

Perroud N, Dayer A, Piguet C, Nallet A, Favre S, Malafosse A, Aubry J-M. Childhood maltreatment and methylation of the glucocorticoid receptor gene NR3C1 in bipolar disorder. Br J Psychiatry 2014; 204(1): 30-35.

DOI: 10.1192/bjp.bp.112.120055

http://bip.rcpsych.org/content/204/1/30\#fn-2

Retraction: DOI: 10.1192/bjp.205.2.164a

http://bip.rcpsych.org/content/205/2/164.2

The charge to access the notice: US $\$ 30$ (for one day)

\section{BJPsych}

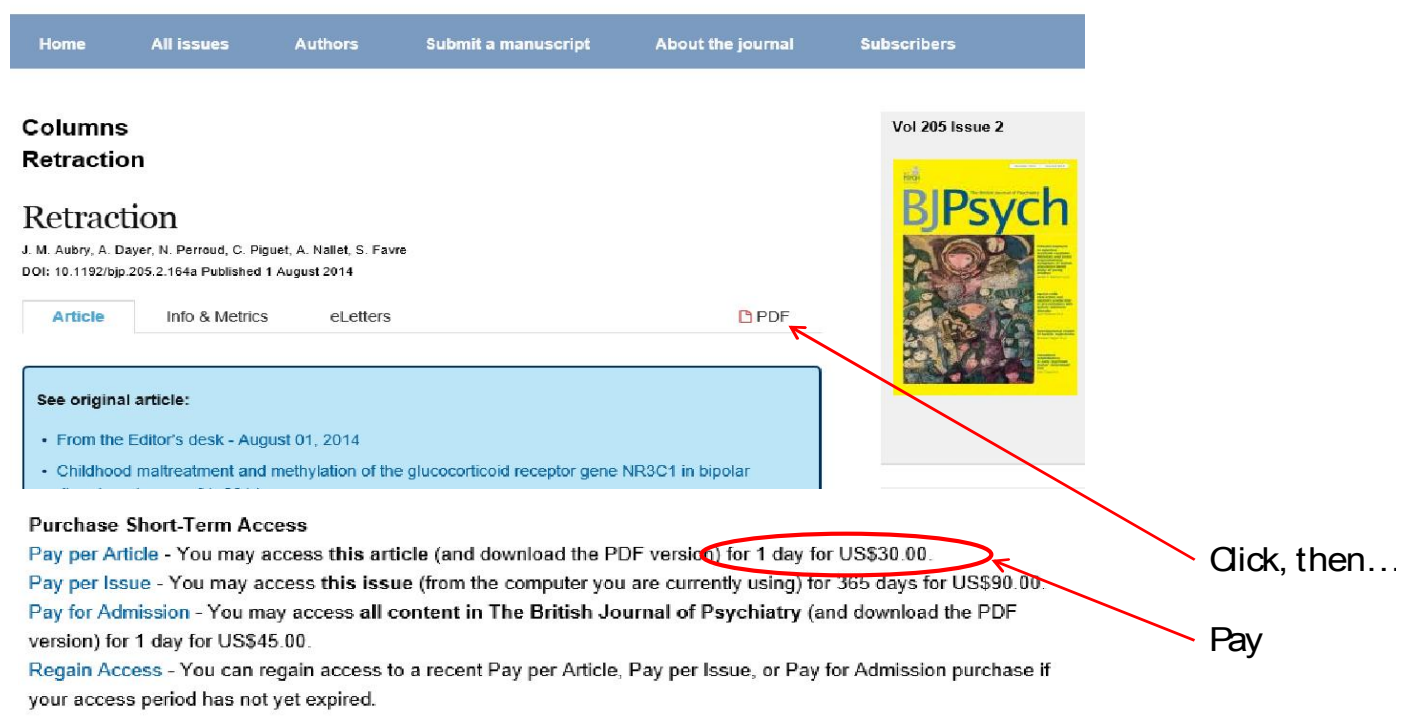


Case 6 (Wiley)

Publisher is COPE member? Yes

Journal is COPE member? Yes

Liu Z, Wang Y, Deng Z, Liu T. High-level production of 3-hydroxypropionatein Escherichia coli and Saccharomyces cerevisiae by introducing part of the 3-hydroxypropionate/4-hydroxybutyrate cycle from Metallosphaera sedula. Biotech Bioeng 2014; 111: 1906. DOI: 10.1002/bit.25275

Retraction: http://onlinelibrary.wiley.com/doi/10.1002/bit.25275/abstract

The charge to access the notice: US $\$ 38$

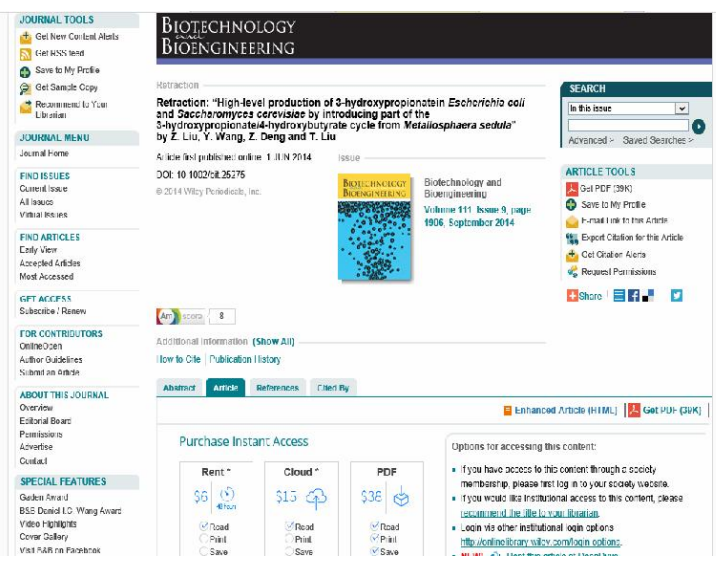




\section{Case 7 (Springer)}

Publisher is COPE member? Yes

Journal is COPE member? Yes

Hu J, Qiu X-J, Li R-X. Nematic ordering pattern formation in the process of self-organization of microtubules in a gravitational field. J Biol Phys 2007; 33(1): 97. DOI: 10.1007/s10867-007-9044-1

Retraction: http://link.springer.com/article/10.1007\%2Fs10867-007-9044-1

The charge to access the notice: US $\$ 39.95$

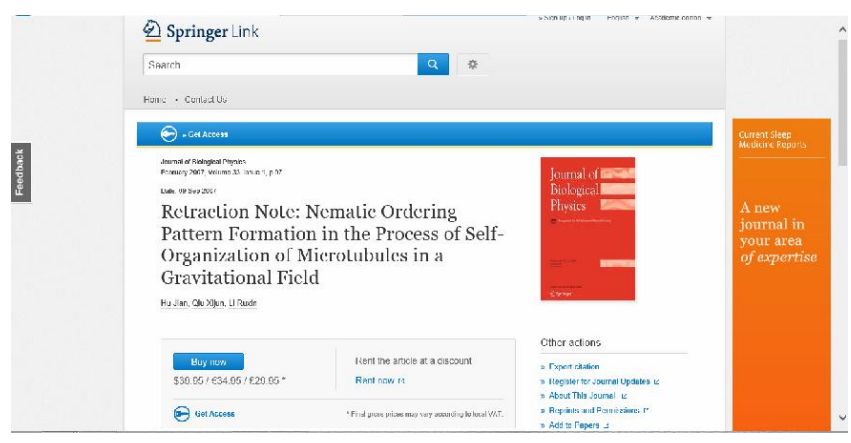


Case 8 (Wiley)

Publisher is COPE member? Yes

Journal is COPE member? Yes

Iorio L. A new type of misconduct in the field of the physical sciences: The case of the pseudonyms used by I. Ciufolini to anonymously criticize other people's works on arXiv. J Assoc Inf Sci Technol 2014; 65(11): 2375. DOI: 10.1002/asi.23238

Retraction (labelled as a withdrawal): http://onlinelibrary.wiley.com/doi/10.1002/asi.23238/abstract

The charge to access the notice: US $\$ 38$

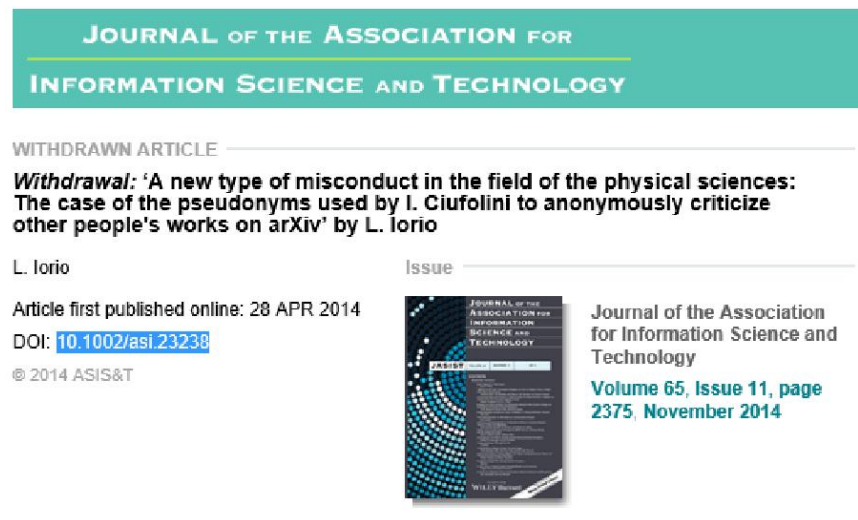

\section{(Am) 3 score $\longdiv { 2 7 }$}

Additionall Information (Show All)

Journal of the Association for Information Science and Technology

Volume 65, Issue 11, Article first published online: 28 APR 2014

Abstract | References | Cited By

\section{asiset}

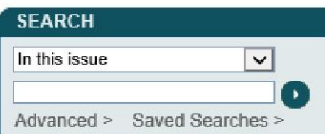

ARTICLE TOOLS

D. GofPDF (31K) 6 Save to My Profile

E-mail Link to this Article

4h. Export Cit a jon for this Article

+ Get Citation Alerts

- Request Permisstipns

+Share 目 f

Purchase Instant Access

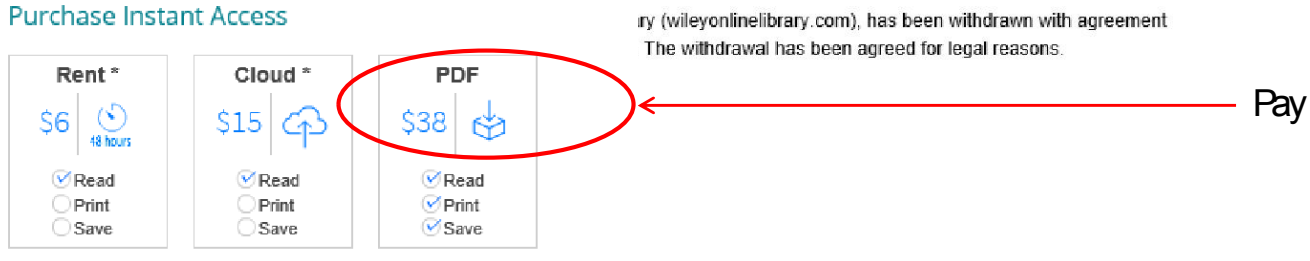


Case 9 (Mary Ann Liebert, Inc. publishers)

Publisher is COPE member? No

Journal is COPE member? No

Trapasso F, Aqeilan RI, luliano R, Visone R, Gaudio E, Ciuffini L, Alder H, Paduano F, Pierantoni GM, Soddu S, Croce CM, Fusco A. Targeted disruption of the murine homeodomain-interacting protein kinase-2 causes growth deficiency in vivo and cell cycle arrest in vitro. DNA Cell Biol 2009; 28(4): 161-167. DOI: 10.1089/dna.2008.0778 http://online.liebertpub.com/doi/abs/10.1089/dna.2008.0778

Retraction: DNA and Cell Biology. March 2014, 33(3), 189-189

http://online.liebertpub.com/doi/full/10.1089/dna.2008.0778.retract

The charge to access the notice: US $\$ 51$ ( $24 \mathrm{~h}$ access)

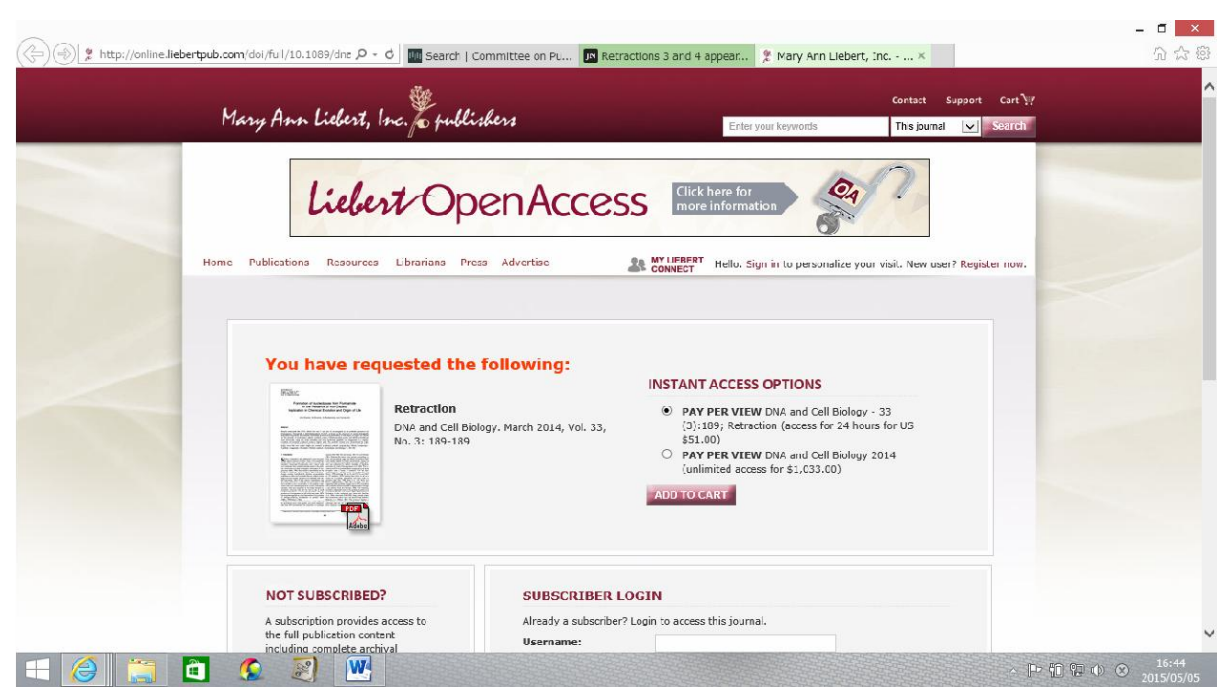


Case 10 (SAGE)

Publisher is COPE member? Yes

Journal is COPE member? Yes

Guo K, Jiang Y-B, Zhou Z-W, Li Y-G. Nut consumption with risk of hypertension and type 2 diabetes mellitus: A meta-analysis of prospective cohort studies. Eur J Prev Cardiol 2013; August 8: 2047487313501120. DOI:

$10.1177 / 2047487313501120$

http://cpr.sagepub.com/content/early/2013/08/08/2047487313501120.abstract

Retraction: http://cpr.sagepub.com/content/early/2013/08/08/2047487313501120/suppl/DC1

The charge to access the notice: US $\$ 36$ ( $24 \mathrm{~h}$ access)

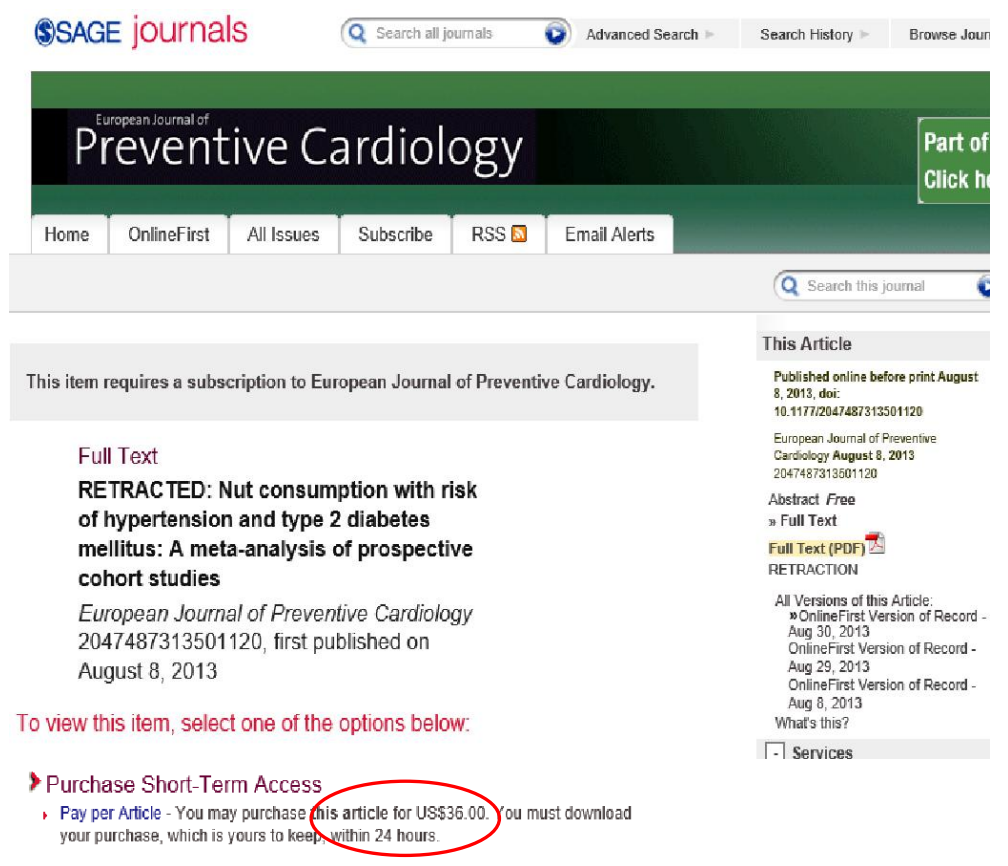

